\title{
We Need an Academic Revolution
}

Nicholas Maxwell

Oxford Magazine, No. 309, 2011, pp. 15-18. http://philpapers.org/archive/MAXWNA.1.doc

\section{Damaging Irrationality of Academia}

Universities today betray both reason and humanity.

They are still dominated by the idea, inherited from the past, that the best way the academic enterprise can help promote human welfare is, in the first instance, to pursue the intellectual aim of acquiring knowledge. First, knowledge and technological know-how are to be acquired; then, secondarily, they can be applied to help solve social problems. But academic inquiry conducted in this way - knowledge-inquiry as it may be called - violates the most elementary rules of reason that one can think of and, as a result, betrays the interests of humanity.

Four absolutely elementary rules of rational problem-solving are:

(1) Articulate, and try to improve the articulation of, the problem to be solved;

(2) Propose and critically assess possible solutions;

(3) If the problem to be solved proves intractable, tackle preliminary, simpler problems in an attempt to work gradually towards the solution to the basic problem to be solved; break the problem up into parts; engage in specialized problem-solving, in other words.

(4) Whenever (3) is implemented, ensure that basic and specialized problem-solving interact, so that each influences the other.

Any problem-solving enterprise which persistently violates one or other of (1) to (4) is irrational, and will suffer as a result. Knowledge-inquiry - academic inquiry as at present constituted - is so seriously irrational that it violates three of the above four elementary rules of reason.

If academia has, as its basic humanitarian aim, to help promote human welfare, then the problems that, fundamentally, need to be solved are problems of living, problems people encounter in their lives. Furthermore, problems of living are solved by what we do, or refrain from doing. Even where new knowledge or technological know-how is required, as it is in medicine, for example, or agriculture, it is always what this knowledge enables us to do that solves our problem of living, and enables us to achieve what is of value, and not the knowledge or the technology as such.

Thus, a kind of academic inquiry rationally devoted to human welfare, rationally devoted to helping people realize what is genuinely of value in their lives, would give absolute intellectual priority to the intellectual activities of:

(1) Articulating, and improving the articulation of, the problems of living that need to be resolved if people are to achieve what is of value in life;

(2) Proposing and critically assessing possible solutions - possible actions, policies, political programmes, new or modified institutions, philosophies of life.

Academic inquiry would also, of course, engage in specialized problem-solving. It would: 
(3) Engage in a multitude of specialized research devoted to acquiring specialized knowledge and technological know-how.

But it would also:

(4) Ensure that basic and specialized problem-solving interact.

Academia today puts (3) into effect splendidly, thus creating an intricate maze of ever more specialized research. But it fails lamentably to implement (1) and (2), and thus fails to put (4) into practice as well. Some policy research does go on in universities, it is true, but at the periphery, almost as an afterthought, and hardly at the centre of the academic endeavour, at an intellectually more fundamental level than natural science. It is not even intellectually fundamental within social science. Nor does policy research exercise much influence over the priorities of research in the natural and technological sciences, as required by rule (4).

In short, when judged from the standpoint of helping to promote human welfare, academic inquiry as it exists by and large today, the outcome of putting knowledge-inquiry into practice, violates three of the four most elementary rules of rational problem-solving conceivable. ${ }^{1}$

\section{Disastrous Human Consequences}

This long-standing, structural irrationality of academia is no mere formal matter. It has led to profoundly damaging consequences for the modern world. For it has led to a kind of academic research which has been extraordinarily successful in developing knowledge and technological know-how, but in a manner which is almost entirely dissociated from a more fundamental concern with our problems of living and what we need to do to resolve them especially those problems created by the application of new knowledge and technology.

Almost all our current global problems are the outcome. The explosive growth of the world's population, the development and spread of modern armaments and the lethal character of modern warfare, the destruction of natural habitats and rapid extinction of species, immense inequalities of wealth and power around the globe, pollution of earth, sea and air, and above all global warming and all the disasters for humanity that that threatens to unleash: all these global problems have arisen because some of us have acquired unprecedented powers to act, via science and technology, without also acquiring the capacity to act wisely. We have failed to develop institutions of learning rationally devoted to helping us enhance our powers so to resolve our global problems. Even worse, we have failed even to see the need to do this. There is no general appreciation of the point that universities, devoted primarily to the pursuit of knowledge, are an intellectual and humanitarian disaster when judged from the standpoint of helping us solve our global problems and thus make progress towards a better world.

But, it may be objected, we must first acquire knowledge, simply in order to know what our problems are, let alone know what we need to do about them. The pursuit of knowledge must come before, and must be intellectually more fundamental than, thought about problems of living.

Even if this argument was valid, it would not tell against the point that academia needs to include sustained exploration of policy problems and options if it is to help promote human welfare in an intellectually rigorous way. But the argument is not valid. In order to know what knowledge it is relevant to try to acquire, we need first to have some provisional idea as 
to what our problems are, and what we might do about them. In order to tackle our problems of living rationally, we need to be able to act in the world, imagine possible actions and, as we proceed, acquire relevant knowledge (at least to some extent). Knowledge (in the form of propositions) is not a prerequisite for action Action and the capacity to act are intellectually more fundamental than propositional knowledge, in the sense that the latter presupposes the former. Dissociated from our capacity to act in the world, from life, propositions are just marks on paper devoid of meaning and content. "Knowing how" is intellectually more fundamental than "knowing that" to put it in terms introduced by Gilbert Ryle. ${ }^{2}$

\section{Wisdom-Inquiry: Problem-Solving Rationality}

As a matter of utmost urgency for the future of humanity, we need to bring about a revolution in our universities. The central and fundamental intellectual task needs to be to articulate problems of living - individual, social and global - and propose and critically assess possible solutions, possible actions, policies, political programmes, institutional changes, philosophies of life. This needs to be the task of social inquiry and the humanities, at the heart of the academic enterprise, intellectually more fundamental than natural and technological science. The pursuit of knowledge of both natural and social phenomena would emerge out of, and feed back into, the intellectually fundamental activity of tackling problems of living (although the pursuit of knowledge should not, of course, be restricted to what we judge to be relevant to current problems of living, and knowledge and understanding can be of value in their own right).

What really matters, of course, is the thinking we engage in as we live, at the individual, social and global level, guiding our actions. It is this socially active thinking we need to improve. The whole point of academic thought ought to be to help improve humanity's socially active thinking guiding action. Academic problem-solving is a specialized bit of human problem-solving quite generally; there thus needs to be a two-way interaction between the two, in accordance with rule (4). The proper basic task of universities is public education about what our problems are, and what we need to do about them, by means of discussion and debate. Universities need to become somewhat like people's civil services, doing openly for the public what actual civil services are supposed to do, in secret, for governments. Academia would have just sufficient power to be independent of government, industry, the military, the media and the public, but no more.

The outcome of modifying knowledge-inquiry just sufficiently to ensure that all four rules of reason are implemented may be called wisdom-inquiry.

\section{The Source of the Problem: the Traditional Enlightenment Programme}

If the above argument is valid, and academia, as it exists at present, really is irrational in the gross, structural and extremely damaging way I have indicated, when and how, it may be asked, did this extraordinary situation arise in the first place?

I now answer this question. My answer will further clarify what is wrong with academia today, and what we need to put in its place.

It all goes back to the $18^{\text {th }}$ century Enlightenment. The philosophes of the French Enlightenment in particular - Voltaire, Diderot, Condorcet and the rest - had the magnificent idea that we should learn from scientific progress how to achieve social progress towards an 
enlightened world. In order to develop this profoundly important idea properly, the following three steps need to be got right.

(i) The progress-achieving methods of science need to be correctly identified.

(ii) These methods need to be correctly generalized so that they become fruitfully applicable to any human endeavour, whatever the aims may be, and not just applicable to the endeavour of improving knowledge.

(iii) The correctly generalized progress-achieving methods then need to be exploited correctly in the great human endeavour of trying to make social progress towards an enlightened, wise, civilized world.

Unfortunately, the philosophes of the $18^{\text {th }}$ century Enlightenment got all three points wrong. And as a result these blunders, undetected and uncorrected, are built into the intellectual-institutional structure of academia as it exists today.

First, the philosophes failed to capture correctly the progress-achieving methods of natural science. From D'Alembert in the $18^{\text {th }}$ century to Karl Popper in the $20^{\text {th }}$, the widely held view, amongst both scientists and philosophers, has been (and continues to be) that science proceeds by assessing theories impartially in the light of evidence, no permanent assumption being accepted by science about the universe independently of evidence. Preference may be given to simple, unified or explanatory theories, but not in such a way that nature herself is, in effect, assumed to be simple, unified or comprehensible. This orthodox view, which I call standard empiricism is, however, untenable. If taken literally, it would instantly bring science to a standstill. For, given any accepted fundamental theory of physics, T, Newtonian theory say, or quantum theory, endlessly many empirically more successful rivals can be concocted which agree with $\mathrm{T}$ about observed phenomena but disagree arbitrarily about some unobserved phenomena, and successfully predict phenomena, in an ad hoc way, that T makes false predictions about, or no predictions. Physics would be drowned in an ocean of such empirically more successful rival theories.

In practice, these rivals are excluded because they are disastrously disunified. Two considerations govern acceptance of theories in physics: empirical success and unity. In demanding unity, we demand of a fundamental physical theory that it ascribes the same dynamical laws to the phenomena to which the theory applies in addition to empirical success. But in persistently accepting unified theories, to the extent of rejecting disunified rivals that are just as, or even more, empirically successful, physics makes a big persistent assumption about the universe. The universe is such that all disunified theories are false. It has some kind of unified dynamic structure. It is physically comprehensible in the sense that explanations for phenomena exist to be discovered.

But this untestable (and thus metaphysical) assumption that the universe is physically comprehensible is profoundly problematic. Science is obliged to assume, but does not know, that the universe is comprehensible. Much less does it know that the universe is comprehensible in this or that way. A glance at the history of physics reveals that ideas have changed dramatically over time. In the $17^{\text {th }}$ century there was the idea that the universe consists of corpuscles, minute billiard balls, which interact only by contact. This gave way to the idea that the universe consists of point-particles surrounded by rigid, spherically 
symmetrical fields of force, which in turn gave way to the idea that there is one unified selfinteracting field, varying smoothly throughout space and time. Nowadays we have the idea that everything is made up of minute quantum strings embedded in ten or eleven dimensions of space-time. Some kind of assumption along these lines must be made but, given the historical record, and given that any such assumption concerns the ultimate nature of the universe, that of which we are most ignorant, it is only reasonable to conclude that it is almost bound to be false.

The way to overcome this fundamental dilemma inherent in the scientific enterprise is to construe physics as making a hierarchy of metaphysical assumptions concerning the comprehensibility and knowability of the universe, these assumptions asserting less and less as one goes up the hierarchy, and thus becoming more and more likely to be true, and more nearly such that their truth is required for science, or the pursuit of knowledge, to be possible at all. In this way a framework of relatively insubstantial, unproblematic, fixed assumptions and associated methods is created within which much more substantial and problematic assumptions and associated methods can be changed, and indeed improved, as scientific knowledge improves. Put another way, a framework of relatively unspecific, unproblematic, fixed aims and methods is created within which much more specific and problematic aims and methods evolve as scientific knowledge evolves. There is positive feedback between improving knowledge, and improving aims-and-methods, improving knowledge-about-howto-improve-knowledge. This is the nub of scientific rationality, the methodological key to the unprecedented success of science. Science adapts its nature to what it discovers about the nature of the universe.

This hierarchical conception of physics, which I call aim-oriented empiricism, can readily be generalized to take into account problematic assumptions associated with the aims of science having to with values, and the social uses or applications of science. It can be generalized so as to apply to the different branches of natural science. Different sciences have different specific aims, and so different specific methods although, throughout natural science there is the common meta-methodology of aim-oriented empiricism.

So much for the first blunder of the traditional Enlightenment, and how to put it right. ${ }^{3}$

Second, having failed to identify the methods of science correctly, the philosophes naturally failed to generalize these methods properly. They failed to appreciate that the idea of representing the problematic aims (and associated methods) of science in the form of a hierarchy can be generalized and applied fruitfully to other worthwhile enterprises besides science. Many other enterprises have problematic aims - problematic because aims conflict, and because what we seek may be unrealizable, undesirable, or both. Such enterprises, with problematic aims, would benefit from employing a hierarchical methodology, generalized from that of science, thus making it possible to improve aims and methods as the enterprise proceeds. There is the hope that, as a result of exploiting in life methods generalized from those employed with such success in science, some of the astonishing success of science might be exported into other worthwhile human endeavours, with problematic aims quite different from those of science.

Third, and most disastrously of all, the philosophes failed completely to try to apply such generalized, hierarchical progress-achieving methods to the immense, and profoundly problematic enterprise of making social progress towards an enlightened, wise world. The aim of such an enterprise is notoriously problematic. For all sorts of reasons, what constitutes a good world, an enlightened, wise or civilized world, attainable 
and genuinely desirable, must be inherently and permanently problematic. Here, above all, it is essential to employ the generalized version of the hierarchical, progress-achieving methods of science, designed specifically to facilitate progress when basic aims are problematic. It is just this that the philosophes failed to do. Instead of applying the hierarchical methodology to social life, the philosophes sought to apply a seriously defective conception of scientific method to social science, to the task of making progress towards, not a better world, but to better knowledge of social phenomena. And this ancient blunder, developed throughout the $19^{\text {th }}$ century by J.S. Mill, Karl Marx and many others, and built into academia in the early $20^{\text {th }}$ century with the creation of the diverse branches of the social sciences in universities all over the world, is still built into the institutional and intellectual structure of academia today, inherent in the current character of social science.

\section{Wisdom-Inquiry: Aim-Pursuing Rationality}

Properly implemented, in short, the Enlightenment idea of learning from scientific progress how to achieve social progress towards an enlightened world would involve developing social inquiry, not primarily as social science, but rather as social methodology, or social philosophy. A basic task would be to get into personal and social life, and into other institutions besides that of science - into government, industry, agriculture, commerce, the media, law, education, international relations - hierarchical, progress-achieving methods (designed to improve problematic aims) arrived at by generalizing the methods of science. A basic task for academic inquiry as a whole would be to help humanity learn how to resolve its conflicts and problems of living in more just, cooperatively rational ways than at present. The fundamental intellectual and humanitarian aim of inquiry would be to help humanity acquire wisdom wisdom being the capacity to realize (apprehend and create) what is of value in life, for oneself and others, wisdom thus including knowledge and technological know-how but much else besides.

One outcome of getting into social and institutional life the kind of aim-evolving, hierarchical methodology indicated above, generalized from science, is that it becomes possible for us to develop and assess rival philosophies of life as a part of social life, somewhat as theories are developed and assessed within science. Such a hierarchical methodology provides a framework within which competing views about what our aims and methods in life should be - competing religious, political and moral views - may be cooperatively assessed and tested against broadly agreed, unspecific aims (high up in the hierarchy of aims) and the experience of personal and social life. There is the possibility of cooperatively and progressively improving such philosophies of life (views about what is of value in life and how it is to be achieved) much as theories are cooperatively and progressively improved in science.

Wisdom-inquiry, because of its greater rigour, has intellectual standards that are, in important respects, different from those of knowledge-inquiry. Whereas knowledge-inquiry demands that emotions and desires, values, human ideals and aspirations, philosophies of life be excluded from the intellectual domain of inquiry, wisdom-inquiry requires that they be included. In order to discover what is of value in life it is essential that we attend to our feelings and desires. But not everything we desire is desirable, and not everything that feels good is good. Feelings, desires and values need to be subjected to critical scrutiny. And of 
course feelings, desires and values must not be permitted to influence judgements of factual truth and falsity.

Wisdom-inquiry embodies a synthesis of traditional Rationalism and Romanticism. It includes elements from both, and it improves on both. It incorporates Romantic ideals of integrity, having to do with motivational and emotional honesty, honesty about desires and aims; and at the same time it incorporates traditional Rationalist ideals of integrity, having to do with respect for objective fact, knowledge, and valid argument. Traditional Rationalism takes its inspiration from science and method; Romanticism takes its inspiration from art, from imagination, and from passion. Wisdom-inquiry holds art to have a fundamental rational role in inquiry, in revealing what is of value, and unmasking false values; but science, too, is of fundamental importance. What we need, for wisdom, is an interplay of sceptical rationality and emotion, an interplay of mind and heart, so that we may develop mindful hearts and heartfelt minds (as I put it in my first book What's Wrong With Science?). It is time we healed the great rift in our culture, so graphically depicted by C. P. Snow.

In recent years there have been a number of developments in universities that can be interpreted as first steps towards putting problem-solving wisdom-inquiry into practice, as I indicated in an article in The Oxford Magazine in 2009 (290, pp. 16-19). These developments include new institutions to tackle problems of global warming, the environment, global health and other policy issues such as peace and wellbeing, and growing concern to promote public engagement with science. My own university has recently even produced a policy document entitled "Developing a culture of wisdom at UCL". But these changes are scattered, faltering, minimal, and lack any sense of the magnitude of what needs to be done. What we need, and at present singularly lack, is a high-profile campaign in support of bringing about sweeping changes to academia so that we may come to possess what we so urgently require: institutions of learning rationally devoted to helping us create a better, wiser world.

\footnotetext{
${ }^{1}$ For further details see my From Knowledge to Wisdom: A Revolution for Science and the Humanities, Blackwell, Oxford, 1984; $2^{\text {nd }}$ extended edition, Pentire Press, London, 2007.

${ }^{2}$ For more details see ref. 1, ch. 8.

${ }^{3}$ For further details see my The Comprehensibility of the Universe: A New Conception of Science, Oxford University Press, 1998; Is Science Neurotic?, Imperial College Press, 2004; and ref. 1, especially chs. 5, 9, and $2^{\text {nd }}$ ed., ch. 14.
} 